\title{
Vírus do mosaico severo do caupi-CPSMV como molécula carreadora para a p28 do vírus da artrite-encefalite caprina-CAEV
}

\author{
Cowpea severe mosaic virus CPSMV as a carrier molecule to p28 from caprine \\ arthritis-encephalitis virus-CAEV
}

\author{
Francisco Jarbas Santos de Sousa ${ }^{1}$ Marcelo Róseo de Oliveira ${ }^{2}$ Ney de Carvalho Almeida ${ }^{1}$ \\ Marlos Gomes Martins ${ }^{3}$ Maria Erivalda Farias de Aragão ${ }^{1}$ \\ Maria Fátima da Silva Teixeira ${ }^{1}$ Maria Izabel Florindo Guedes ${ }^{4}$
}

\section{RESUMO}

$O$ vírus da Artrite-encefalite caprina (CAEV) pertence à família Retroviridae, gênero Lentivirus. O CAEV infecta caprinos do mundo inteiro causando artrite, encefalite, mamite, pneumonia e emagrecimento progressivo. Este trabalho mostra a formação de uma quimera construída através da mistura da p28 do CAEV com glutaraldeído e CPSMV, purificada por meio de cromatografia em biogel e sephadex G-150. As cromatografias foram monitoradas através de leituras em espectrofotômetro no comprimento de onda de 280nm, dos líquidos coletados nos tubos. Os picos contendo a quimera foram coletados e submetidos à eletroforese (SDS-PAGE), sendo assim evidenciada a banda correspondente à mesma. Grupos de camundongos swiss foram imunizados com o vírus quimérico (CPSMV + p28), com o vírus CPSMV purificado e com a proteína p28 do $C A E V$, utilizando o adjuvante de Freund incompleto. Os anticorpos específicos produzidos contra o CPSMV e p28 reconheceram a proteína quimérica em Western Blotting e em teste de ELISA. Os anticorpos contra o vírus quimérico apresentaram títulos mais elevados do que os anticorpos produzidos contra a p28, demonstrando que o vírus quimérico apresenta maior imunogenicidade do que a proteína p28 sozinha. Os resultados mostraram que o acoplamento covalente entre o CPSMV e a p28 do CAEV foi obtido com sucesso, originando uma molécula estável não comprometendo a estrutura do capsídeo do CPSMV. Desta forma, sugere-se que o CPSMV possa ser utilizado como molécula carreadora na produção de vacinas para vírus que infectam animais.

Palavras-chave: $C P S M V, p 28, C A E V$, quimeras, ligação covalente, imunização.

\section{ABSTRACT}

Caprine arthritis-encephalitis virus (CAEV) belongs to Retroviridae family, Lentivirus genus. This virus infects caprine all over the world causing arthritis, encephalitis, mammitis and progressive emaciating. This research showed chimera's building made by mixing up CAEV p28, with glutaraldehyde, and CPSMV, purified through the chromotography in biogel and sephadex $(G-150)$. After that, some measures in a spectrophometric were developed to absorbance at 280nm. Peaks, which contained chimera, were collected and submitted to SDS-PAGE, evidencing the band relative to itself. Groups of swiss mice were immunized with chimeric virus, purified CPSMV and with p28 protein using incomplete Freund Adjuvant. CPSMV and p28 specific antibodies recognized chimeric protein in Western Blotting and ELISA showing the efficacy of the method. The results showed the covalent coupling between CPSMV and CAEV p28 was successfully archieved, originating a stable molecule, which no disestablished the capside from CPSMV. Besides, it showed that chimeric virus presents more immunogenicity than protein p28 isolated. It's suggesting CPSMV can be used as a carrier molecule in the production of vaccines to the virus, which infect animals.

Key words: $C P S M V, p 28, C A E V$, chimeric, covalent bind, immunization.

\section{INTRODUÇÃO}

A artrite encefalite caprina (CAE) é uma doença específica de caprinos, afetando-os em todo o

${ }^{1}$ Programa de Pós-graduação em Ciências Veterinárias, Universidade Estadual do Ceará, Fortaleza, CE, Brasil.

${ }^{2}$ Ciências Biológicas, Universidade Estadual do Ceará, Fortaleza, CE, Brasil.

${ }^{3}$ Programa de Pós-graduação em Microbiologia Médica, Universidade Federal do Ceará, Fortaleza, CE, Brasil.

${ }^{4}$ Universidade Estadual do Ceará, Fortaleza, CE, Brasil. Autor para correspondência. Endereço: Rua Bernardo de Figueiredo 2588

Ap.102; 60455-440, Brasil. E-mail: florinfg@terra.com.br 
mundo, tendo como principais sinais clínicos: artrite, encefalite, mamite, emagrecimento crônico dos animais adultos e mais raramente pneumonia progressiva (FRANKE, 1998). Esta doença é causada por um vírus RNA, pertencente ao gênero Lentivirus da família Retroviridae, muito semelhante ao Maedi/Visna dos ovinos (CRAWFORD et al., 1980; NORMAN \& SMITH, 1983). Ainda não existe tratamento e nem vacina para esta enfermidade e uma das grandes dificuldades para produzi-la tem sido a baixa imunogenicidade deste vírus. Devido aos prejuízos econômicos causados por ele, torna-se necessário o desenvolvimento de uma vacina eficaz para a prevenção da doença .

Os vírus que infectam os vegetais têm ultimamente despertado grande interesse para os imunologistas, pela possibilidade de serem usados como veículos ou vetores para expressar antígenos na produção de vacinas para animais e/ou humanos (MOFFAT, 1995; MODELSKA et al., 1998). O uso de vírus de planta para estes propósitos apresenta grandes vantagens sobre as técnicas que utilizam outros microrganismos, uma vez que os mesmos não ocasionam doenças em humanos e animais. Ademais, os vírus de planta podem ser multiplicados rapidamente e com menor custo além de serem estáveis e de fácil purificação (FLORINDO et al., 2002). Muitos vírus de plantas têm sido utilizados como vetores para expressar fragmentos de proteínas antigênicas em sua superfície (SCHOLTHOF et al., 1996; YUSIBOV et al.,1997 e BERGER et al., 2001), ou simplesmente como moléculas carreadoras, através de ligações covalentes, como sugerido por (FLORINDO et al., 2002).

O vírus do mosaico severo do Caupi (CPSMV) é um vírus RNA, apresentando capsídeos não envelopados com partículas icosaédricas de 28 a $30 \mathrm{~nm}$ de diâmetro, pertencente ao gênero Comovirus e à família Comoviridae. (MURPH et al., 1995). Este vírus foi recentemente apontado como uma eficiente molécula carreadora, uma vez que se mostrou inócuo para os camundongos, mas induziu uma resposta imunológica com altos títulos de $\operatorname{IgG}$ e $\operatorname{IgA}$ e não induziu a formação de IgE (FLORINDO et al., 2002).

Considerando a baixa imunogenicidade do CAEV (ADAMS et al., 1980) e o alto poder imunogênico do CPSMV, o objetivo deste trabalho é relatar uma experiência de inserção da proteína p28 do CAEV. Segundo LEVY (1993), é uma proteína estrutural do capsídeo dos lentivirus que possui peso molecular de aproximadamente $28 \mathrm{KDa}$, no capsídeo do CPSMV através de ligação covalente com glutaraldeído, e estudar a eficácia do mesmo como molécula carreadora.

\section{MATERIAL E MÉTODOS}

Material vegetal e procedimento de purificação O material foliar infectado com o CPSMV foi cedido pela Universidade Federal do Ceará. O vírus CPSMV foi mecanicamente inoculado em plantas de Vigna unguiculata (L) Walp. para sua multiplicação. A purificação do vírus foi de acordo com o método descrito por FLORINDO et al. (2002).

\section{Proteína $\mathrm{p} 28$}

A proteína p28 Lot. 126, utilizada neste trabalho, foi comercialmente adquirida do Institut Pourquier-Montpellier - França.

Produção da quimera

O CPSMV foi covalentemente acoplado com a proteína p28 do capsídeo do vírus da artrite encefalite caprina de acordo com a metodologia empregada por McKENZIE et al. (1984). Foram incubados $200 \mu \mathrm{L}$ de solução contendo $400 \mu \mathrm{g}$ de p28; $10 \mu \mathrm{L}$ de glutaraldeído $25 \%$ e $200 \mu \mathrm{L}$ de tampão fosfato $0,1 \mathrm{M}, \mathrm{pH} 6,8$, que permaneceram toda à noite em temperatura ambiente $\left(25^{\circ} \mathrm{C}\right)$ e na ausência de luz. No dia seguinte, a mistura foi aplicada a uma coluna de "biogel dextrana blue" calibre p-100, arquitetada em uma pipeta de $10 \mathrm{~mL}$ e equilibrada com tampão PBS (0,01M fosfato de sódio; $0,1 \mathrm{M} \mathrm{NaCl}, \mathrm{pH} 7,3)$. A eluição das frações foi realizada com PBS e visualizada por espectrofotômetro a $280 \mathrm{~nm}$. Uma amostra de $200 \mu \mathrm{L}$ de solução de CPSMV contendo $400 \mu \mathrm{g}$ de proteína viral foi diluída em $1 \mathrm{~mL}$ de PBS e $200 \mu \mathrm{L}$ de tampão 1M carbonato, pH 9,5 e em seguida adicionada ao pico II da cromatografia "biogel dextrana blue" calibre p-100, correspondente à p28 covalentemente ligada ao glutaraldeído. A mistura foi incubada por 24 horas a $4^{\circ} \mathrm{C}$ e aplicada em uma coluna de "Sephadex Dextran Blue" G-150, arquitetada em seringa de $5 \mathrm{~mL}$ e equilibrada com PBS. A quimera (CPSMV-P28) foi eluída em um só pico.

\section{Eletroforese SDS-PAGE}

As proteínas dos capsídeos virais do CPSMV, p28 do CAEV e a quimera (CPSMV + p28\}, antes e depois da separação em coluna de Sephadex Dextran Blue" G-150 foram analisadas em gel de poliacrilamida, contendo duodecil sulfato de sódio (SDS-PAGE) com o gel de concentração a $4 \%$ e o gel de separação a $12 \%$, de acordo com o método descrito por (LAEMMLI, 1970).

Imunização subcutânea

Três grupos de dez camundongos "swiss" fêmeas com 7 a 8 semanas de idade foram imunizados 
por via subcutânea, na região dorsal, com o CPSMV purificado $(10 \mu \mathrm{g}$ de proteína), com a proteína p28 do CAEV $(10 \mu \mathrm{g})$ e com quimera $(10 \mu \mathrm{g})$, utilizando o adjuvante de Freund incompleto. Os animais receberam reforços 21 e 35 dias após o início da imunização e foram realizadas coletas de sangue nos dias 7, 14, 21, 28,35 e 42 pós-imunização. O soro pré-imune foi coletado antes do início da imunização.

ELISA

Os anticorpos produzidos em camundongos, foram submetidos ao teste de ELISA indireto (Enzyme Linked Immunosorbent Assay). Para esse ensaio, as placas foram sensibilizadas com cada antígeno $(0,5 \mu \mathrm{g} /$ orifício $)$ conforme descrito por FLORINDO et al. (2002).

Western blotting

Para a realização do teste de western blotting, foram utilizadas proteínas do CPSMV e p28 e Quimera. As proteínas foram submetidas à eletroforese em gel de poliacrilamida a $4-12 \%$ (SDS-PAGE), como descrito anteriormente, e depois transferida para uma membrana de nitrocelulose conforme TOWBIN et al. (1979). A membrana foi imersa em tampão PBS-molico (5\%) contendo os anticorpos produzidos em camundongos contra o CPSMV ou contra a proteína p28. Foram utilizados anticorpos anti-IgG de camundongo ligado à peroxidase, produzido em cabra da Sigma.

\section{RESULTADOS}

Após ativação da p28 com glutaraldeído, foi realizada uma cromatografia de bio-gel que mostrou que houve formação de polímeros de peso molecular mais elevado, os quais foram eluídos no pico I e monômeros de p28 eluídos no pico II conforme os resultados apresentados na figura 1. A mistura pico II + CPSMV foi submetida a uma cromatografia em coluna de Sephadex G-150 revelando a presença de 2 picos, sendo que o CPSMV acoplado covalentemente a proteína p28 foram eluídos no primeiro pico, como mostra a figura 2 .

O perfil eletroforético em SDS-PAGE da mistura de p28 ativada com glutaraldeído mais o CPSMV, antes de ser submetida a uma cromatografia de Sephadex G-150, revelou a migração de duas frações protéicas de massas moleculares aproximadamente estimadas em 116 e 55KDa respectivamente (Linhas 3 e 8 da Figura 3). Após passagem na coluna, foi observada a migração protéica de apenas uma fração, com massa molecular estimada em 116kDa (Linhas 1 , 2, 6 e 7 da Figura 3), enquanto o CPSMV puro

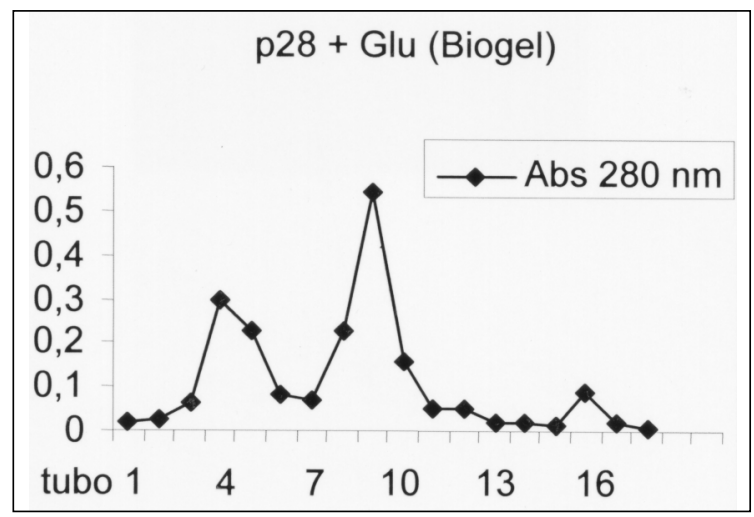

Figura 1 - Cromatografia de $410 \mu \mathrm{L}$ da amostra de p28 e glutaldeido, em coluna de Biogel-P-100, equilibrada com PBS. Volume total da coluna foi de $10 \mathrm{~mL}$ e o volume das frações coletadas foi de $1 \mathrm{~mL}$

apresentou três frações protéicas de 44, 23 e $21 \mathrm{KDa}$ (Figura 3, linhas 4 e 9).

A figura 4 mostra a cinética da síntese de anticorpos policlonais, induzida em camundongos imunizados com $10 \mu \mathrm{g}$ de proteínas da quimera, $10 \mu \mathrm{g}$ de CPSMV e 10ìg da proteina p28. Podem ser observadas as respostas primárias e secundárias específicas dos anticorpos reativos com o CPSMV, com a p28 e com a quimera. Os títulos dos anticorpos contra a quimera (CPSMV + p28) e contra o CPSMV são mais elevados do que os títulos dos anticorpos apresentados contra a p28 sozinha.

$\mathrm{O}$ teste de Western blotting mostra que os anticorpos anti-CPSMV reconheceram especificamente o vírus (Figura $5 \mathrm{~A}$ - linha 4) e a fração protéica de $116 \mathrm{KDa}$ (Figura 5A- linhas 1, 2 e 3), mas não reconheceram a fração de $55 \mathrm{KDa}$. Por outro lado, os anticorpos anti-p28 reconheceram a fração de 116KDa

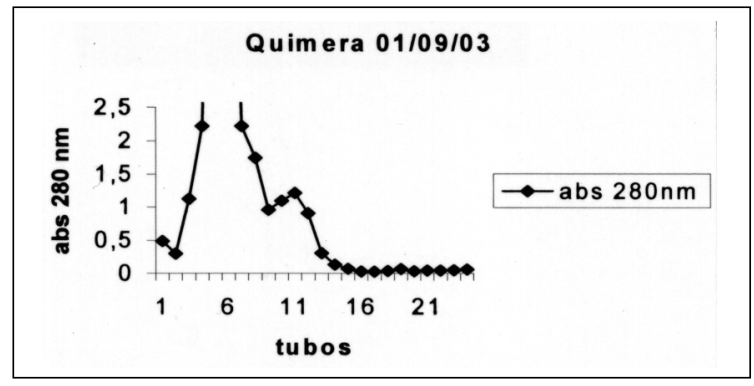

Figura 2 - Filtração em gel da preparação do conjugado CPSMV + p28. Uma coluna de $10 \mathrm{~mL}$ foi preparada usando Sephadex G-150, equilibrada com PBS. A amostra aplicada para ser eluída foi de $4 \mathrm{~mL}$. As amostras coletadas foram de aproximadamente $1 \mathrm{~mL}$ para cada tubo.

Ciência Rural, v.35, n.6, nov-dez, 2005. 


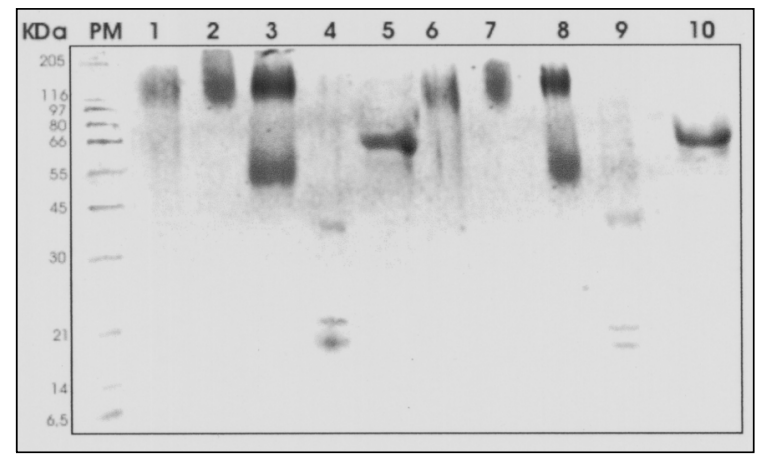

Figura 3 - Perfil eletroforético em SDS-PAGE das frações eluídas nas cromatografias. Nos poços 1,2, 6 e 7-quimera purificada $(2 \mu \mathrm{g})$; poços 3 e 8 - CPSMV + p28, antes da filtração em Sephadex G-150 $(2 \mu \mathrm{g})$; poços 4 e 9 -CPSMV $(1 \mu \mathrm{g})$, poços 5 e $10-$ p28 $(2 \mu \mathrm{g})$

e a fração de 55KDa (Figura 5B-linhas 1 e 3). Além de reconhecer a fração correspondente à p28 (Figura 5Blinha 5).

\section{DISCUSSÃO}

Os resultados do presente estudo mostraram que o CPSMV pode funcionar como uma efetiva molécula carreadora. Isto porque foi capaz de formar uma quimera estável com a proteína p28 do CAEV, através de ligações covalentes com o glutaraldeído. Vários estudos têm mostrado que o glutaraldeído, por possuir grupos carbonílicos expostos em suas extremidades pode funcionar como

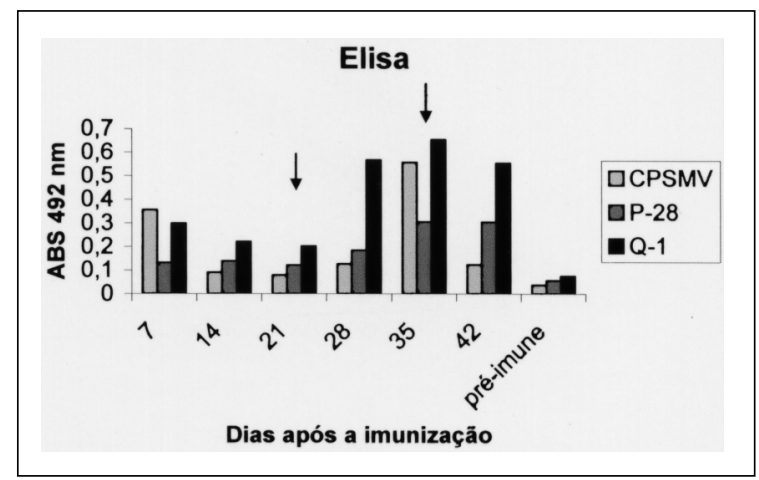

Figura 4 - Teste de Enzyme linked immunosorbent assay (ELISA) indireto com anticorpos policlonais de camundongos imunizados com 10ig de Quimera (CPSMV+P28), camundongos imunizados com 10ìg de CPSMV e camundongos imunizados com 10 ìg de p28, com adjuvante de Freund incompleto, na diluicão de 1:40, mostrando reações específicas contra o CPSMV (), P28 ( $\left.\begin{array}{l}1 \\ 1\end{array}\right)$ e Quimera ( $\left(\begin{array}{l}1 \\ 1\end{array}\right)$. As setas indicam os dias em que os animais receberam reforços. ligante entre duas proteínas com aminoácidos que possuem grupos aminos $\mathrm{NH}_{2}$ expostos (McKENZIE et al., 1984; HAMAJINA et al., 1995; CUMMINGS et al., 1991). As seqüências de aminoácidos do CPSMV (CHEN \& BRUENING, 1992) e da proteína 28 do CAEV (SALTARELLI et al., 1990) mostram que ambas possuem várias lisinas e argininas, que são aminoácidos que apresentam o grupo $\mathrm{NH}_{2}$ em suas extremidades, facilitando a formação das ligações covalentes com grupo carbonílico do glutaraldeído.

A figura 3- linhas 3 e 8 mostra a migração de duas frações protéicas de 116 e 55KDa sugerindo que a fração maior corresponde ao vírus quimérico. Esta possibilidade foi confirmada após passagem em cromatografia Sephadex G-150, onde o vírus quimérico foi eluído no primeiro pico (Figura 2). O produto desta coleta foi submetido em gel de eletroforese e apresentou a migração de uma única fração protéica de $116 \mathrm{KDa}$, que foi reconhecido em teste de Western blotting por anticorpos específicos para o CPSMV e p28 como mostram as figuras 5A -linhas 1 e 2 e 5Blinhas 1 e 3 . Por outro lado observa-se que a fração protéica de 55KDa mostrada na (Figura 3-linhas 3 e 8), corresponde a polímeros de $\mathrm{p} 28$, uma vez que a mesma foi reconhecida especificamente por anticorpos antip28 (Figura 5B-linhas 1 e 3) e não foi reconhecida por anticorpos anti-CPSMV (Figura 5A-linhas 3). Estes resultados comprovam a ocorrência da ligação do CPSMV com a proteína p28, uma vez que o CPSMV apresenta três polipeptídios de pesos moleculares correspondentes a 44, 23 e 21KDa (Linha 4 da Figura.3) e a fração correspondente a p28 apresentou peso

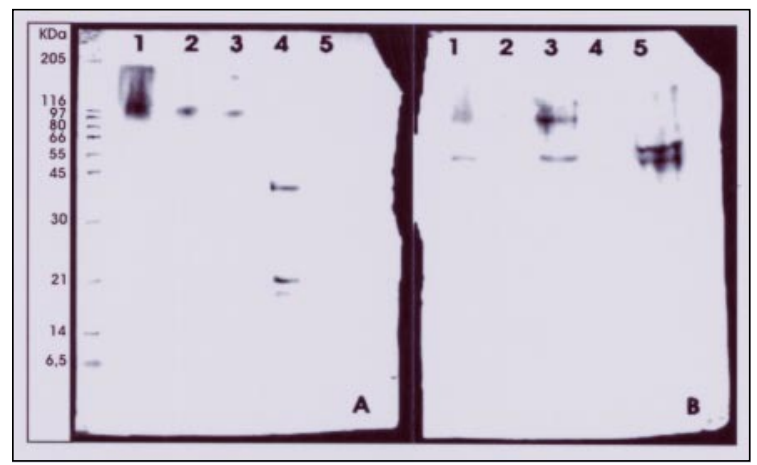

Figura 5-Western blotting mostrando que a Quimera (CPSMV+P28) é reconhecida por anticorpos antiCPSMV (A)-Nos poços 1 e 2 (quimera), poço 3 (CPSMV + p28, antes da filtração em Sephadex G150), poço 4 (CPSMV) e no poço 5 (p28). Em (B) a quimera é reconhecida por anticorpos anti-p28: poço 1 e 3 (CPSMV + p28, antes da filtração em Sephadex G-150), poço 4 (CPSMV) e poço 5 - p28.

Ciência Rural, v.35, n.6, nov-dez, 2005. 
molecular de aproximadamente 55 a $60 \mathrm{KDa}$ (Linhas -5 e 10 da Figura-3). Como o peso molecular da p28 é de 25 a $28 \mathrm{KDa}$ (LEVY, 1993), sugere-se que pode ter ocorrido a formação de polímeros que não foram separados.

A imunização de camundongos com a quimera mostrou que a mesma induziu uma resposta imunológica humoral com síntese de anticorpos com títulos mais elevados, quando comparados com a p28 e CPSMV nas mesmas condições, além de apresentar maior estabilidade (Figura 4). Isto sugere que o acoplamento covalente da p28 ao CPSMV potencializa a resposta imunológica, aumentando a síntese de anticorpos após o primeiro e segundo reforços. Estes resultados são interessantes quando comparados com os obtidos por QUERAT \& VIGNE (1992), que mostraram que os anticorpos neutralizantes contra CAEV são muito lentos para inativar a sua infectividade, por este vírus ser particularmente protegido dos anticorpos, através do alto teor de carboidratos contidos em sua superfície.

O aumento da imunogenicidade da p28 mostra que este procedimento pode ser importante para possibilitar a produção de uma vacina para o vírus $\mathrm{CAEV}$, assim como desenvolver métodos de diagnósticos efetivos. Estes resultados são de grande importância uma vez que antígenos de CAEV induzem uma resposta imunológica com anticorpos de baixos títulos e demonstraram um declínio a partir de 8 a 21 dias (ADAMS et al., 1980).

Conclui-se que a ligação covalente entre o CPSMV e a p28 foi eficaz na formação de uma quimera imunogênica, visto que a mesma foi capaz de imunizar camundongos contra a p28 como mostram os testes de ELISA e Western blotting sugerindo a possibilidade de uso como antígenos para diagnósticos e vacinas.

\section{REFERÊNCIAS}

ADAMS, D.S. et al. Immune responses of goats persistently infected with caprine arthritis-encephalitis virus. Infection and immunity, Washington, v.28, n.2, p.421-427, 1980.

BERGER, N. et al. Characterization of chimeric enzymes between caprine arthritis virus, maedi-visna virus and human immunodeficiency virus type 1 integrases expressed in Escherichia coli. Journal of General Virology, v.82, p.139-148, 2001.

CHEN, X.; BRUENING, G. Nucleotide sequence and genetic map of cowpea sever mosaic virus RNA2 and comparison with RNA2 of other comoviruses. Virology, v.187, p.682692, 1992.

CRAWFORD, T.B. et al. Chronic arthritis in goats caused by a retrovirus. Science, v.207, p.997-999, 1980.
CUMMINGS, J. et al. Covalent coupling of doxorubicin in protein microspheres is a major determinant of tumour drug disposition. Biochemical Phamacology, v.41, n.12, p.18491854, 1991 .

FLORINDO, M.I.G. et al. Immune response induced in mice by oral immunization with cowpea severe mosaic virus. Brazilian Journal of Medical and Biological Research, v.35, p.827-835, 2002 .

FRANKE, C.R. Controle sanitário da artrite-encefalite caprina. Salvador: EDUFBA, 1998. 70p.

HAMAJIMA, K. et al. A macromolecular multicomponent peptide vaccine prepared using the glutaraldehyde conjugation method with strong immunogenicity for HIV-1. Clinical Immunology and Immunopathology, v.77,n.3, p.374-379, 1995.

LAEMMLI, U.K. Cleavage of structural proteins during the assembly of the head of bacteriophage T4. Nature, v.227, p.680, 1970.

LEVY, J.A. Pathogenesis of human immunodeficiency virus infection. Microbiology, v.57, p.183-289, 1993.

McKENZIE, S.J. et al. Cholera toxin B subunit as a carrier protein to stimulate a mucosal immune response. Journal of Immunology, v.133, p.1818-1824, 1984

MODELSKA, A. et al. Imunization against rabies with plantderived antigen. Proc Natl Acad Sci USA, v.95, n.5, p.24812485, 1998 .

MOFFAT, A.S. Exploring transgenic plants as a new vaccine source. Science, v.268, p.558-660, 1995.

MURPHY, F.A. et al. Virus taxonomy. Sixth report of the international committee on taxonomy of viruses. New York: Springer Verlag, 1995. 341p.

NORMAN, S.; SMITH, M.C. Caprine arthritis encephalitis: review of the neurologic form in 30 cases. Journal American Veterinary Medicine Association, v.182, p.1342-1345, 1983.

SALTARELLI, M. et al. Nucleotide sequence and transcriptional analysis of molecular clones of CAEV which generate infectious virus. Virology, v.179, p.347-364, 1990.

SCHOLTHOF, H.B. et al. Plant virus vectors for transient expression of foreign proteins in plants. Annu Rev Phytopathol, v.34, p.229-152, 1996.

TOWBIN, J. et al. Electrophoretic transfer of proteins from polyacrylamide gels to nitrocellulose sheets: procedure and some applications. Proc Natl Acad Sci, USA, v.76, p.43504354, 1979

YUSIBOV, V. et al. Antigens produced in plants by infection with chimeric plant viruses immunize against rabies virus and HIV-1. Proc Natl Acad Sci, USA, v.94, p.5784-5788, 1997.

QUERAT, G.; VIGNE, R. Caprine arthritis encephalitis virus. In: ROBERT, G. et al. Encyclopedia of virology. Academic, 1992. Cap.1, p.1-13. 